\title{
Quantifying the Influence of Road Geometric Parameters on Road Safety (Case Study: Hawassa-Shashemene-Bulbula Rural Two-Lane Highway, Ethiopia)
}

\author{
Mandefro Terefe Abebe \\ Department of Civil Engineering, Hawassa University, Hawassa, Ethiopia \\ Email: mandefroterefe@yahoo.com
}

How to cite this paper: Abebe, M.T. (2019) Quantifying the Influence of Road Geometric Parameters on Road Safety (Case Study: Hawassa-Shashemene-Bulbula Rural Two-Lane Highway, Ethiopia). Journal of Transportation Technologies, 9, 354-380.

https://doi.org/10.4236/jtts.2019.93023

Received: December 20, 2018

Accepted: July 20, 2019

Published: July 23, 2019

Copyright $\odot 2019$ by author(s) and Scientific Research Publishing Inc. This work is licensed under the Creative Commons Attribution International License (CC BY 4.0).

http://creativecommons.org/licenses/by/4.0/

\begin{abstract}
Road safety depends on humans, vehicles, and highway conditions. These factors influence road safety separately or in combination. Despite these facts, the police report indicated that only a single cause of accident has been reported for a given accident in Ethiopia and the number of accidents that had been caused by road defect accounted around 1\% of total accidents per year, which underestimates its contribution to road accidents. Beside these facts, only a few studies were carried out in Ethiopia on this issue. Even though dangerous road segments were identified and ranked along the same study area of this paper in our previous publication, Hawassa-Shashemene-Bulbula two-lane rural highway, the influences of road geometric parameters on road safety were not correlated along this study area. Therefore, it is imperative to clarify the relationship between the expected number of traffic accidents and the geometric conditions of the road under study to reduce accidents and provide safe driving environment. The main objective of this study was to quantify the influence of road geometric parameters on road safety. Using historical accident data, traffic data, and road data, the expected numbers of accidents were estimated by using the empirical Bayes (EB) method. Then, the expected numbers of accidents have been correlated with one or more road geometric parameters at a time. Accordingly, the identified dangerous road segments in the previous publication (DOI: 10.4236/jtts.2018.83009) were further analyzed to estimate the influence of road geometric parameters on road safety based on expected accident frequency. The result of the analysis shows that the radius of horizontal curve, superelevation, transition curve length, lane and shoulder widths were negatively correlated with the expected frequencies of accidents. Whereas the numbers of horizontal and vertical
\end{abstract}


curves per segment, grade of the road, the occurrence of left turn horizontal curves with down grade and right turn horizontal curves with upgrade were positively correlated with the expected number of accidents. Therefore, it has been concluded that the influence of road geometry has significant effect on the occurrence of accidents along this study area.

\section{Keywords}

Road Geometric Parameters, Expected Number of Accidents

\section{Introduction}

The very high cost of highway accidents paid by societies around the world makes highway safety improvement an important objective of transportation engineering. Highway engineers are usually interested in identifying road and traffic factors (which includes pavement condition, road geometry and its environmental, lane and shoulder width, number of traffic and its composition) to improve roadway design for new roads and provide a safer driving environment for existing roads. The occurrence of road accident is usually caused not only by a single factor rather due to the convergence of a series of events. A framework for relating the series of events in a road crash to the categories of crash-contributing factors is the Haddon Matrix [1]. According to this matrix, the factors that may cause to road crashes are generally categorized into three types, such as: 1) Human Factors, 2) Vehicle Factors, and 3) Roadway/Environment Factors. According to the Highway Safety Manual (HSM) [2], three percent (3\%) of road crashes have been occurred due to only roadway factors, but thirty-four percent (34\%) of road crashes have been occurred due to the combination of roadway, vehicle and human factors. In relation to this, Berhanu [3] cited (Downing et al., 1991) the cause of road accidents that were identified by the police in ten developing countries and the UK. The report indicated that the sum of the causes of accidents in UK only exceeds 100\% (accounted 131\%) owing to more than one identified causing factors of accidents.

Accidents are rarely caused because of one single factor; therefore, a multi-disciplinary approach is essentially needed to understand the problems and provide better and appropriate solutions. According to Berhanu's study in Ethiopia [3], traffic police officer usually reported what they consider the primary cause of road accident for a given accident. Accordingly, the police indicated a single cause of accident but they failed to list multiple factors involved as on-the-spot investigations of individual accident. Furthermore, his study indicated that due to road defect only $1 \%$ of total accidents were reported in Ethiopia. This was because of the police report provided some insight into what the police considered as the major factor involved in road accident.

Despite poor condition of roads in developing countries, traffic police report indicated that due to road defect only around $0.9 \%$ of average yearly total acci- 
dents were occurred in Ethiopia between 2008/09 and 2012/13, which underestimate its contribution to road accidents. This is may be due to the fact that the police officer did not identify the road factors as the cause of traffic accidents. Moreover, this was not because the road condition in Ethiopia was absolutely safe, but this was due to lack of some aspects of relationship between road and traffic engineering factors and traffic accidents. Contrary to this problem, however, only few studies were carried out in Ethiopia, in this regard, the Berhanu's dissertation on the effect of road and traffic factors on road safety in the selected main road sites and junctions in the city of Addis Ababa and along Addis Ababa-Nazareth (or Adama) two-lane rural road in 2000 could be worth mentioning. In addition to this, even though dangerous road segments have been identified and ranked on Hawassa-Shashemene-Bulbula two-lane rural highway with total length of $64.5 \mathrm{~km}$, in our previous publication [4], the influence of road section parameters on road safety have not been correlated along this study area even by any other study. Therefore, due attention should be given to identify the broader underlying inter-related factors contributing to the rising magnitude and burden of road traffic accidents in Ethiopia.

The main focus of this study was to quantify the influence of road geometric parameters on road safety for, especially, the identified and ranked dangerous road segments in the previous study. Accordingly, the safety level of each read segment was quantified by using empirical Bayes (EB) method and then correlated with road geometric parameters along this study area. Accordingly, it tried to fill the gap of knowledge by using state of the art approach called EB method, which integrate risk factors associating to the influence of road, traffic related factors and historical accident data to quantify the safety level of the road instead of using only historical accidents. Moreover, the estimation of road safety by using EB method considers the random nature of accidents and correct regression-to-the-mean bias. To this end, the findings of this study believed to be useful for further implementation of the road safety measures as effective as possible to provide a safer driving environment, to improve roadway design while the concerned authority designs a new road, and a baseline for similar studies. Furthermore, it gives some lesson for the client of the road and also any road agencies while they plan, design and implement any road safety engineering activities because most road agencies in Ethiopia have used traditional approaches, like frequencies and severities of short term accidents, to analyze the safety of the road.

\section{Literature Review}

The relations between road section characteristics and number of accidents have been reported in several studies. The character of the studies varies in types of roads studied, number of road characteristics and choice of method of analysis. In spite of the said variations, the literature still provides an estimate of which characteristics are expected to influence the number of accidents on a certain road section. 


\subsection{Road Geometric Parameters}

A study in Sweden by Elvik [5] indicated that the length of the curve, the curve radius, whether spiral transition curves are used, and the super-elevation of the roadway affects the safety along a horizontal curve. Accordingly, for a given curve deflection, crashes are more likely on curves with a smaller radius; spiral transitions decrease crashes; and insufficient super-elevation increases crashes. Other studies indicated that radius of path, curve length of path, number of curves in the path, number of horizontal curves that are very close to each other and interference of horizontal and vertical curves have significant roles in the occurrence of accidents [6] [7] [8]. Other studiesss also revealed that the crash frequency increased as the horizontal curve radius decreased, the length of the vertical curve increased, and the sharpness of the vertical curve increased [9]. The following section describes the effect on safety of improving the characteristics of the road's horizontal and vertical alignment and their combination, as well as cross-sections characteristics.

According to the cited research findings by Elvik [5], the accident rates on horizontal curves are up to four times higher than tangent sections. Sharp horizontal curves tend to have higher accident rates than flatter horizontal curves. Grade sections generally have higher accident rates than level sections; steep grades have higher accident rates than mild grades, and downgrades have higher accident rates than upgrades. Poor sight distances are associated with traffic accidents. The provision of transition curves and super-elevation as per the design standard on horizontal curves and speed consistency in the alignment of the road are vital in order to enhance road safety [3].

\subsubsection{Horizontal Curve Elements}

Radius of horizontal curves. Research results showed that the number of road accidents tends to decrease when the radii of horizontal curves increase [6] [7] [8] [10] [11] [12]. The effect of horizontal curves of low radii lead to road safety problems, hence small radii have been characterized by a higher accident frequency as well as accident severity [8] and the related risk rates increased significantly for radii less than $200 \mathrm{~m}$ [10]. According to Berhanu [3], for curve radii less than $200 \mathrm{~m}$, the accident rate is at least twice as high as that of $400 \mathrm{~m}$. For radii greater than about 400 to $500 \mathrm{~m}$, an increase in radius leads to lower-rate of safety gain. Other studies also concluded that the safety benefit becomes less in radii above $400 \mathrm{~m}$ [12]. Other study cited by Berhanu in Germany indicated that an increase of radius up to $400 \mathrm{~m}$ the accident rate drops to about $30 \%-40 \%$ of the value for radii less than $100 \mathrm{~m}$ and large radii up to $1000 \mathrm{~m}$ result in further slight reduction in accident risk. Other studies also stated that horizontal curves have higher crash rates than straight sections of similar length and traffic composition; this difference becomes apparent at radii less than $1000 \mathrm{~m}$ [8]. However, increasing the radius in curves with radii greater than 2000 meters has no effect on the occurrence of accidents [5]. 
Transition curves (clothoides): A clothoides eliminate the need for abrupt movements in order to negotiate the curve and therefore to enhance safety [13]. Accordingly, transition curves are a requirement only for trunk and link road segments having a design speed of equals to or greater than $80 \mathrm{~km} / \mathrm{hr}$ for Ethiopian roads. Elvik [5] reviewed one study in America, by Zegeer et al. 1991, that the effect of constructing transition curves in the form of clothoides reduces the number of accidents by $10 \%$ (lower $95 \%$ limit $15 \%$, upper $95 \%$ limit $7 \%$ ). On the other hand, a few studies concluded that transition curves were dangerous because of driver underestimation of the severity of the horizontal curvature [14] [15].

Super-elevation: According to several studies, super-elevation is defined as a road's transverse incline toward the inside of a horizontal curve in order to counteract the centrifugal force and increases the safety performance of highway sections as well as the riding comfort [8] [10]. As stated in [11] [16], the lowest "safe radius" can be computed by using the maximum allowed super-elevation and a "conservative" value for the side friction for various design speeds. As per the cited studies in [10], it was study found that the number of accidents on wet pavements to be abnormally high in curves with a super-elevation of less than $2 \%$. Other study reported that improving the super-elevation reduces the number of accidents by $5 \%$ to $10 \%$.

\subsubsection{Vertical Curve Elements}

Gradients. Studies indicated that accidents occur more frequently on gradients than on level sections [17]. Elvik [5] showed that reducing gradient reduces the number of accidents. The effect was greater for the steepest gradients and decreases thereafter. Other study indicated that the accident frequency increased with gradient and down-gradients have considerably higher crash rates than up-gradients [8]. As Elvik demonstrated, on up-gradients stretches, the accident rate was around 7\% lower than for similar down-gradients stretches (lower 95\% limit 13\%, upper 95\% limit 0\%).

\subsubsection{Horizontal and Vertical Curves}

Number of curves: As reviewed in [8], one study investigated the relation between the number of curves and the number of accidents. The result showed that roads with many curves have been characterized by fewer accidents than roads with few curves. Other studies also concluded that the number of curves and other curve parameters such as sum of curve length and average of central angle were the most important factors influencing accident frequency index [7]. Other studies reviewed in [10] demonstrated that if a sharp curve has located on a road with low average curvature (i.e. long preceding tangents), accident risk has increased significantly [18] [19]. One study conducted on traffic accidents along dangerous roads in Amman-Jordon revealed that number of vertical and horizontal curves were responsible for causing traffic accidents at hazardous locations [20]. 
Combination of horizontal and vertical alignment. An inefficient combination of horizontal and vertical alignments may lead to road safety problems, even when the horizontal and the vertical alignment are separately correct and constructed according to the guidelines [10]. In addition, poor coordination of horizontal and vertical alignments can create locations where the available sight distance drops below the required sight distance [21]. In particular, the coincidence of a horizontal and a crest vertical curve may, under certain conditions, lead to significant limitation of the available sight distance and prevent the prompt perception of the curve. Similarly, the coincidence of a horizontal and a sag vertical curve may create a false impression of the degree of curvature (i.e. the horizontal curve may seem to have a higher radius than the actual), and may contribute to increased accident rates [22] [23]. The result of one study indicated that short horizontal curves at sharp sag vertical curves and short horizontal curves at sharp crest vertical curves have been associated with higher crash frequencies [9].

\subsubsection{Lane and Shoulder Width}

Lane and shoulder width: According to HSM [2], run-off the road and opposite direction accidents are the primary accident types affected by lane or shoulder width or both. These accident types decrease with both increasing lane width and shoulder width; however, the marginal effect of their increment diminishes as either the base lane width or the base shoulder width increases [8]. Furthermore, HSM indicated that the base lane width is $3.66 \mathrm{~m}$ and the base shoulder width equals to $1.83 \mathrm{~m}$.

Berhanu [3] reviewed two studies on two-lane low volume rural roads in USA that $3.0 \mathrm{~m}$ lane widths with narrow or no shoulder have higher accident rate than $2.7 \mathrm{~m}$ lane width with any shoulder width. As he indicated, this was due to the reason that wide carriageway may encourage lane changing maneuvers and/or higher speeds. In contrast, $3.3 \mathrm{~m}$ and $3.6 \mathrm{~m}$ lane widths, in general, have significantly lower accident rates than that of $3.0 \mathrm{~m}$ lane width. He also summarized the result of other studies that for $3.0 \mathrm{~m}$ lane, a shoulder of $1.5 \mathrm{~m}$ or greater appears to affect the accident rate significantly; however, for $3.3 \mathrm{~m}$ and $3.6 \mathrm{~m}$ lanes, shoulders of $0.9 \mathrm{~m}$ or greater can significantly be effective in accident reduction.

One study [24] summarized the results of several studies that a number of parameters, which includes lane and shoulder width, have significant impact on road accidents. The same study also concluded that wider lanes help in lowering crash rates as it provides a buffer against driver mistakes or distraction. As per the reviewed studies in [8], it has been assumed that wider lanes may provide additional space to the driver to correct potential mistakes and thus avoid crashes. Other studies; however, indicated that a driver could be expected to adapt to the available space, and the positive safety effects from the wider lanes may be offset by the higher speeds [25]. Other studies [26] revealed that lanes wider than $3.70 \mathrm{~m}$ do not contribute to a higher safety because they may result in unsafe 
maneuvers such as over taking despite of oncoming traffic. Moreover, it has been justified that the higher speed on wider lanes could lead to more accidents.

One study evolved Poisson regression model for traffic accidents on two lane rural highways under mixed traffic conditions showed that shoulder width had negative sign, which indicates that increasing shoulder width decreases the accident frequencies [27]. According to Elvik [5], rural roads with hard shoulders (which are usually 0.3-1 meters wide) have an accident rate which is around 5\% $10 \%$ lower than roads without hard shoulders. More three studies reviewed by him indicated that increasing the width of hard shoulder by 0.3 meters appears to reduce the number of injury accidents by about $20 \%$, while increasing the width of hard shoulder by around $1 \mathrm{~m}$ does not lead to statistically significant changes in the total number of accidents (injury and property damage only accidents).

\subsection{Comparison of Before-And-After Studies to Estimate the Safety of the Road}

According to Hauer [28], three types of before-and-after study methods exist in order to evaluate the safety improvement of a given road site. In this study, only two of them have been discussed here under: 1) Simple or naive before-and-after study method and 2) the before-and-after study with empirical Bayes (EB) method.

Simple before-and-after study method is based on the assumption that the crash experience before improvement of a given road is a good estimate of what would have occurred during the after period without improvement [29]. This method simply compares the observed crash data (frequencies and rate) between before and after period was among the earliest practice. Despite easy to use, such comparison usually leads to inaccurate and potentially misleading conclusion because the method may be affected by several factors, especially in case when only short-term data, 2-3 years, are available as cited in several literatures [29] [30] [31]. One of them is its lack of flexibility to account for the effect of change in traffic volume of crash occurrence. Another well-known shortcoming is its incapability of addressing regression-to-the-mean (RTM) bias. RTM bias would be occurred due to random fluctuation of accident occurrence at a given location [31]. This makes likely that road sites with high number of accidents in any one year may show a decreasing trend in the subsequent year even without treatment of the road site [30]. Therefore, safety estimate of only accident count, especially the short term, would be considered as biased estimate of the safety of the selected sites because the accident count regress towards their true long term mean [29].

Before-and-after study with empirical Bayes (EB) method is used to estimate the expected average crash frequency within defined facility limit over a given period of time, for a given geometric design and traffic control features and known traffic data (AADT) [2]. As indicated by Hauer [28] of all the problems associated with the simple before-and-after method, the regression-to-the-mean 
problem is generally considered as the most serious. The before-and-after study with the Empirical Bayes (EB) method has been developed to adjust for the regression-to-the mean bias, the effect of change in traffic volume and the time trend for the occurrence of accidents [28]. The method was based on the following three assumptions:

$>$ The number of observed accidents at any site follows a Poisson distribution;

> The means for a population of systems can be approximated by a gamma distribution; and

Changes from year to year from different factors are similar for all reference sites.

Based on these assumptions, EB method establishes the foundation for the prediction by estimating what the expected frequency of target crashes in the before period was, and on the basis of this foundation, predict how the expected number of crashes would have changed from the before period to the after period as a result of changes in traffic, weather, and other factors [29]. Accordingly, the concept behind the EB method in mitigating the regression-to-the-mean effect is to predict the number of crashes that would have been expected to have occurred during the after period had the treatment not been implemented. This method estimates the safety of a road by using not only the accident count of a given facility but also based on what is known about the safety of similar such types of facilities, to estimate how many expected accidents would have encountered at the treated site had no improvement been made [2] [28] [32] [33]. To overcome the problems of naïve method, several studies have proposed model-based or state of the art approach in order to estimate the safety of a given road sites and concludes that empirical Bayes (EB) approach as the most consistent and reliable method [2] [4] [28] [30] [31] [32] [33]. Despite its reliability, the application of the EB method is not common due to some reasons indicated in several literatures. As indicated in [2] [29] [30] [33] [34], this method is more complex than other methods, needs reliable data (accident count and AADT of each specific site in the most recent years and road geometric data), calibrated Safety Performance Function (SPF) to be fitted purely from the local data, and also trained and experienced personal are required in order to properly implement this method.

\section{Materials and Methods}

\subsection{Description of the Study Area}

Ethiopia is the most populous landlocked country in the world and the second-most populous nation on the African continent. It occupies a total area of 1,127,127 square kilometers, and its capital and largest city is Addis Ababa, with more than 102 million populations [35]. Before 2016, Ethiopian Economy grew at a rate between $8 \%$ and $11 \%$ annually for more than a decade, which indicated one of the fastest growing nations among the IMF member countries [36]. This growth was driven by government investment in infrastructure, as 
well as sustained progress in the agricultural and service sectors. In the last few decades, Ethiopian government focused in the expansion of road infrastructure. Accordingly, the average road network annually raised around 8.5\%between 1997 and 2015. In the fall of 2015, Ethiopia comprises a road network totaling about 110,414 km. Expansion of improved road network always push motorization on the road rapidly and that results in a rapidly increase in road traffic accidents.

This study was conducted in the Oromia regional state along Hawassa-Bulbula trunk road particularly within West Arsi Zone territory. Of this road stretches only the rural two-lane two-way, which had not undergone any modification during the period (2012/13-2014/15), has been selected for this study. It is one of the highest standard rural two-lane highway functional class in the country and the designated part of Trans African highway, which connects Cairo in Egypt and Cape Town in South Africa.

In this study, a rural highway is defined in HSM [2] as a highway passing through the non-urban environment i.e. passing through the village (population of not more than 5000 inhabitant) and rural non-settlement areas. According to ERA [13] functional classification, the roads under study is categorized in to trunk roads, which is one of the highest standard two lane rural roads in the country.

\subsection{Sources of Data}

The data used in this study concern rural two-lane roads and come from two sources:

Primary data: obtained by inspecting and measuring road geometry, roadside hazards and delineation, and field reconnaissance survey to observe the characteristics of traffic.

Secondary data: expected number of accidents and other related data obtained from published article [4], road as built drawing and average Annual Daily Traffic (AADT) collected from Ethiopian Road Authority (ERA).

\subsection{Types of Data}

Two types of data have been used in this study, namely road geometric parameters and expected number of average accidents, in order to attain the stated objective.

\subsubsection{Road Data}

The road parameters that have been used in the subsequent analysis was obtained from both secondary sources (as built drawing of the road, which are owned by ERA) and primary source (obtained from exhaustive field measurement and observation). The chosen road parameters for this study are expected to be most relevant with the occurrence of accident. Accordingly, the safety of the road has been correlated with the following expected main road geometric parameters. 
Horizontal curve elements considered simultaneously on road safety. These parameters are:

- Radius of horizontal curves (R) were categorized into four ranges of radii: 1) $\mathrm{R} \leq 450$ meters, 2) $450 \leq \mathrm{R} \leq 750$ meters, 3) $750 \leq \mathrm{R} \leq 1000$ meters, and 4) $\mathrm{R}$ $\geq 1000$ meters,

- Super-elevation, and

- Length of the curve, which is the sum of circular and transition curves length.

$>$ Number of horizontal and vertical curves per $1.5 \mathrm{~km}$ segment.

> Grade of vertical alignments $(\mathrm{G})$ categorized into three ranges of grades (Accordingly, flat road section ( $\mathrm{G} \leq 3 \%)$, mild $(3 \%<\mathrm{G} \leq 6 \%)$ and rolling $(G>6)$, where $G=$ grade of the road in percent).

$>$ Combination of horizontal and vertical alignment (particularly the coincidence of right horizontal curve and crest vertical curve and left horizontal curve and sag vertical curve).

> Cross-sectional elements (lane width, shoulder width and surfacing), and

$>$ Others pertinent data such as roadside hazard, sight distance, terrains type, land use, speed characteristics, non-motorized traffic and pedestrian characteristics and others were collected through reconnaissance survey and some interview with traffic police officers.

Preparing the data, the road stretch was divided into short sections of $1.5 \mathrm{~km}$ in length based on kilometer post and it has been considered as homogeneous road section since it has the same design standard. In total, 43 road sections (total length $=64.5 \mathrm{~km}$ ) have been considered and these entire road segments were two-lane two-way rural highway.

\subsubsection{Traffic Accident Data}

Since the expected number of accidents with the empirical Bayes (EB) adjustments have been estimated by using road, three years (2012/13-2014/15) traffic accidents and traffic volumes (in terms of AADT) data in our previous publication [4], it has been used for this research as a secondary data.

\subsection{Methods}

In this research, empirical Bays (EB) method was used to quantify the safety level of each road segments. Then, the expected number of accidents have been correlated with the selected road geometric parameters. As indicated in the literature part, the most recently proposed procedures to investigate the safety of road sites have been based on the EB approach, which basically aims to stabilize the random fluctuation in accident count by specifying the safety of a given facility as an estimate of its long-term mean instead of short-term average accident count. Some literature also pointed out that long-term average crash frequency for a given road site would be even better estimate of the safety of that road. However, long-term average crash frequency usually faced some limitations. Accordingly, the cited limitations in the literature indicated that long-term accident records may not be available; the average long-term accident frequency 
may not be precise if the average crash frequency was low; and the geometric, traffic control, land use and other site condition may be changed over time. Therefore, the key advantageous of implementing EB method to evaluate the safety of a given road was to increase precision of estimate, to reduces RTM bias, to use information from the site (short-term accident count) and information from other but similar sites (road geometry, traffic control and other important features) [2] [28].

RTM bias would be occurred due to the fact that one is often interested in the safety of a given road sites that either require attention because they seem to have high number of accidents, or merit attention because they have fewer accidents than expected [28] [32]. To demonstrate the effect of RTM bias, for instance, hypothetical example is illustrated in Figure 1. As the Figure indicated year-to-year fluctuation of observed accidents during consecutive 14-year period for a given site and they range from 1 to 6 in the $3^{\text {rd }}$ and $9^{\text {th }}$ years respectively, with an average of " $E$ " long-term accident counts per year.

It can be seen that if someone proposed and implemented a certain countermeasure at the end of $11^{\text {th }}$ year in response to the higher number of 3-years average before accidents, the result would seem that " $c$ " number of accident reduction have been observed when compared with the number of 3-years average after accidents. Even though the treatment may have some effects, parts of accident reduction was due to RTM effects. Accordingly, out of the total reduction of average accident counts, which is equal to "c" as indicates in Figure 1, between 3-years before and after the implementation of countermeasures, around "a" and "b" number of accident reduction were due to RTM effect and actual

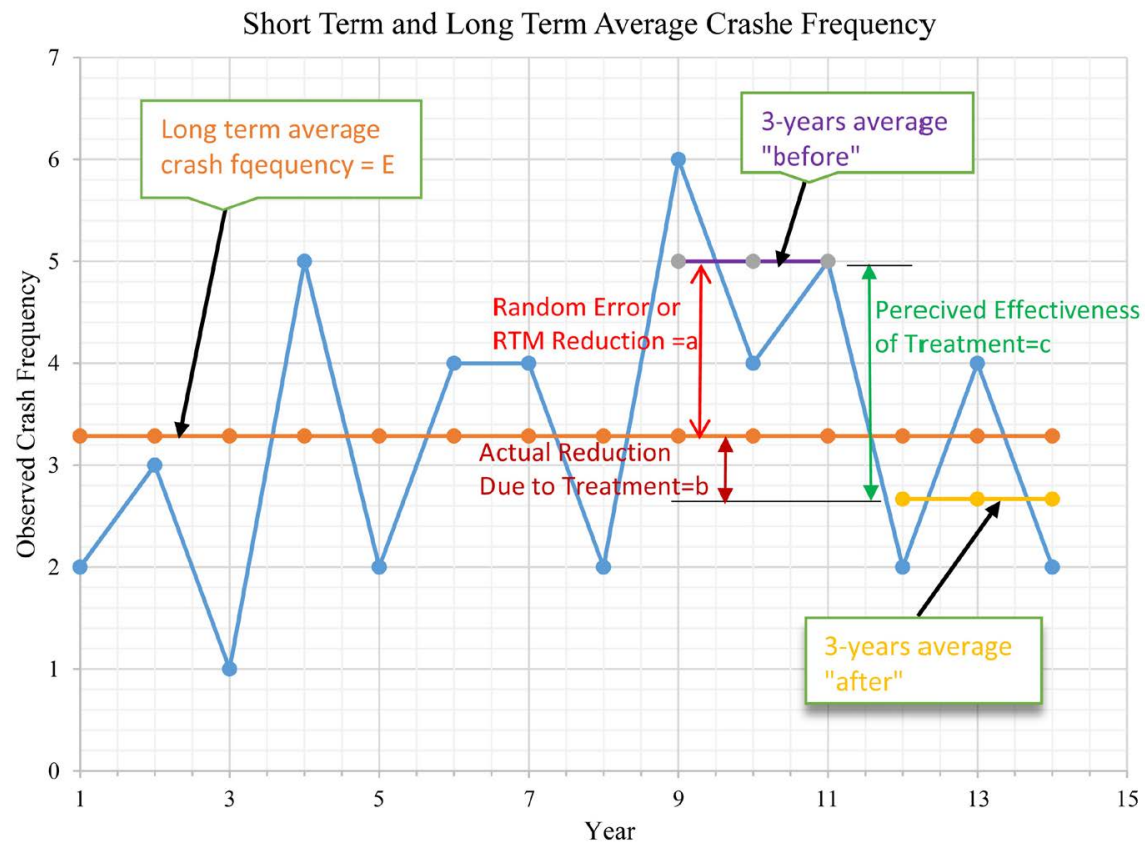

Figure 1. Typical example of regression-to-the-mean effect with average observed long-term and short-term accident frequency. 
reduction due to treatment of the site respectively. As a result, the effectiveness of the treatment would have been overestimated. In general, assuming no safety countermeasures were undertaken, the level of safety may be overestimated or underestimated by an amount equals to short-term (usually 3-years) average minus long-term average accidents. This difference is equal to the amount of random error in the safety estimate. If this random error is significant and positive, one might incorrectly select this location for overestimated countermeasure application. On the other hand, if the random error is negative one might wrongly ignore the location for further countermeasure application [32].

As it has been described in the introduction part, since this study was conducted in the same study area of my previous publication (DOI: 10.4236/jtts.2018.83009) some output results from that article, namely yearly expected average crash frequency with the empirical Bayes EB adjustments, was used as an input of this study. The EB method uses data from the crash history of a treated site, as well as information about the safety of reference sites with similar geometric characteristics. The joint use of the information from treated and reference sites were based on a weighted average of this information [32]. The estimate of the expected number of crashes at the treated site, $E(k / K)$, given the site recorded $K$ crashes, can be estimated by using the following Equations [28]. Furthermore, the detail procedure of how to estimate the EB safety estimate is found in [4].

$$
\begin{gathered}
E(k / K)=w * E(k)+(1-w) * K \\
w=\frac{1}{1+\frac{\operatorname{Var}(k)}{E(k)}}
\end{gathered}
$$

where, $E(k)$ is the expected number of crashes at reference sites; $K$ is the actual crash count at a treated site; $\operatorname{Var}(k)$ is the variance of the expected number of crashes at the reference sites; and $w=$ weight factor, which can also be estimated based on over-dispersion parameter.

The general formula for the accident prediction model, $E(k)$, is composed of three components: 1) base model, 2) accident modification factors, and 3) calibration factor as given by [2]. The HSM Safety Performance Function (SPF) for base condition on rural two-lane two-way highway was calibrated for the local condition and also the fitness of SPF with the local data was confirmed in [4] along the same study area of this study. Accordingly, the predicted number of total roadway accidents per year after the application of calibration factor that has been fitted for the local condition and can be estimated by using Equation (3).

$$
\begin{aligned}
E(k)= & 1.51 *(\mathrm{AADT}) *(L) * 365 * 10^{-6} * \mathrm{EXP}^{-0.321} \\
& *(\mathrm{AMF} 1 \mathrm{~A} * \mathrm{AMF} 2 \mathrm{r} * \cdots * \mathrm{AMFnr})
\end{aligned}
$$

where, $E(k)=$ predicted number of total roadway collisions per year after application of AMFs; AADT = average annual daily traffic; and $L=$ length of segment 
(mile); and AMF1r, $\cdots$, AMFnr $=$ accident modification factors for roadway segments. Any differences in geometric and design features from base condition has been modified by AMFs as indicated in [2] [4].

The selection of various road section parameters was based on exhaustive literature review. Accordingly, in the following section, various road section parameters were examined and assessed, including horizontal and vertical alignment and their combination, as well as cross-sections characteristics.

\section{Results and Discussions}

\subsection{Observed, Predicted and Expected Number of Accidents for the Ranked Dangerous Segments}

The expected number of accidents (i.e. EB safety estimate), which were estimated to be the weighted average of observed and predicted number of accidents, for the ranked dangerous road segments are presented in Table 1 [4]. Therefore, in this study to attain the stated objective the safety level of each road segment has been correlated with one or more road geometric parameters at a time.

\subsection{Influence of Road Geometric Parameters on Road Safety}

Having the identified dangerous road sites or problem locations along the road in the previous study (DOI: 10.4236/jtts.2018.83009), this study established the relationship between the expected number of accidents (i.e. EB safety estimate) and the road characteristics leading to the occurrence of road accidents.

\subsubsection{Influence of Horizontal Alignment Elements on Road Safety}

Figures 2(a)-(d) indicate that the influence of horizontal curve (HC) elements such as curve radius, total curve length (which is the sum of circular and transition curve) and super-elevation on road safety were considered simultaneously. However, since it is difficult to conduct road safety study under a controlled condition, this paper assumed that when the effect on safety of one road parameter has been estimated the effects on safety as not additive due to the improvement of other road parameters. Rather, the contribution of either the joint effect of more than one road parameters or only one road parameter at a time on road safety was computed assuming the other has taken effect.

To do this, the identified dangerous road sites were categorized according to the ranges of radius of horizontal curves because the research results showed that the number of road accidents tends to decreases when the radii of horizontal curves increases as stated by Berhanu, Elvik and others. Accordingly, the influence of radius of horizontal curve and the joint effect of curve length and super-elevation were estimated an increasing order of radius of the curve and presented in the following four ranges of radii: 1) $R \leq 450$ meters, 2) $450 \leq R \leq 750$ meters, 3) $750 \leq \mathrm{R} \leq 1000$ meters, and 4) $\mathrm{R} \geq 1000$ meters. The results of the analysis are given in Figures 2(a)-(d). 
Table 1. Observed, predicted and expected number of accidents for the ranked dangerous segments.

\begin{tabular}{|c|c|c|c|c|c|c|c|}
\hline \multirow{2}{*}{$\begin{array}{l}\text { Segment } \\
\text { Code }\end{array}$} & \multirow{2}{*}{$\begin{array}{c}\text { Observed } \\
\mathrm{K}\end{array}$} & \multirow{2}{*}{$\begin{array}{c}\text { Predicted } \\
\mathrm{E}\{k\}\end{array}$} & \multirow{2}{*}{$\begin{array}{c}\begin{array}{c}\text { EB Safety } \\
\text { estimate }\end{array} \\
\mathrm{E}\{k / \mathrm{K}\}\end{array}$} & \multirow{2}{*}{$\begin{array}{c}\begin{array}{c}\text { Excess } \\
\text { or PSI }\end{array} \\
\mathrm{E}(\mathrm{k} / \mathrm{K})-\mathrm{E}(\mathrm{k})\end{array}$} & \multirow{2}{*}{$\begin{array}{c}\begin{array}{c}\text { Based } \\
\text { on PSI }\end{array} \\
\text { Rank }\end{array}$} & \multicolumn{2}{|c|}{$\begin{array}{c}\text { Excess or PSI } \\
\text { per year (\%) }\end{array}$} \\
\hline & & & & & & Individual & Cumulative \\
\hline 165 & 5.33 & 2.26 & 4.48 & 2.21 & 1 & 14.2 & 14.2 \\
\hline 152 & 6.67 & 4.52 & 6.59 & 2.07 & 2 & 13.3 & 27.5 \\
\hline 151 & 5.00 & 2.17 & 4.24 & 2.06 & 3 & 13.3 & 40.8 \\
\hline 149 & 4.67 & 2.67 & 4.28 & 1.61 & 4 & 10.4 & 51.1 \\
\hline 164 & 3.67 & 1.99 & 3.17 & 1.18 & 5 & 7.6 & 58.7 \\
\hline 154 & 4.67 & 3.50 & 4.61 & 1.12 & 6 & 7.2 & 65.9 \\
\hline 148 & 3.67 & 2.64 & 3.52 & 0.89 & 7 & 5.7 & 71.6 \\
\hline 142 & 3.33 & 2.46 & 3.21 & 0.75 & 8 & 4.8 & 76.4 \\
\hline 138 & 3.67 & 2.98 & 3.65 & 0.67 & 9 & 4.3 & 80.7 \\
\hline 136 & 3.00 & 2.20 & 2.86 & 0.66 & 10 & 4.2 & 85.0 \\
\hline 163 & 2.67 & 1.81 & 2.42 & 0.61 & 11 & 3.9 & 88.9 \\
\hline 166 & 2.33 & 1.72 & 2.16 & 0.44 & 12 & 2.8 & 91.7 \\
\hline 122 & 2.33 & 2.06 & 2.33 & 0.28 & 13 & 1.8 & 93.5 \\
\hline 133 & 2.67 & 2.47 & 2.73 & 0.26 & 14 & 1.6 & 95.1 \\
\hline 161 & 2.00 & 1.74 & 1.96 & 0.21 & 15 & 1.4 & 96.5 \\
\hline 128 & 2.33 & 2.24 & 2.40 & 0.17 & 16 & 1.1 & 97.6 \\
\hline 141 & 2.00 & 1.92 & 2.05 & 0.14 & 17 & 0.9 & 98.4 \\
\hline 170 & 1.67 & 1.60 & 1.69 & 0.08 & 18 & 0.5 & 99.0 \\
\hline 150 & 1.67 & 1.64 & 1.72 & 0.08 & 19 & 0.5 & 99.5 \\
\hline 123 & 2.00 & 2.06 & 2.11 & 0.05 & 20 & 0.3 & 99.8 \\
\hline 131 & 2.33 & 2.46 & 2.48 & 0.02 & 21 & 0.1 & 100.0 \\
\hline 162 & 1.67 & 1.74 & 1.75 & 0.003 & 22 & 0.0 & 100.0 \\
\hline 137 & 2.33 & 2.6 & 2.51 & less than zero & Not D & angerous & - \\
\hline 135 & 2.67 & 3.0 & 2.88 & less than zero & Not $D$ & angerous & - \\
\hline \multicolumn{4}{|c|}{ Total excess EB-adjusted estimate per year } & 15.6 & \multicolumn{2}{|c|}{$\begin{array}{l}\text { Excluding segment } \\
135 \& 137\end{array}$} & 100.0 \\
\hline
\end{tabular}

Source: Abebe, M. T. and Belayneh, M. Z. (2018) Identifying and Ranking Dangerous Road Segments a Case of Hawassa-Shashemene-Bulbula Two-Lane Two-Way Rural Highway, Ethiopia.

1) Radius of the curve up to $450 \mathrm{~m}$.

In this phase, the safety of the road was analyzed an increasing order of the radii of HCs up to $450 \mathrm{~m}$ in three steps. For each step, Figure 2(a) indicates that the joint effect of HC elements such as radius of the curve, total length of curves (include both circular and transition) and super-elevation on road safety are discussed in the following section. 


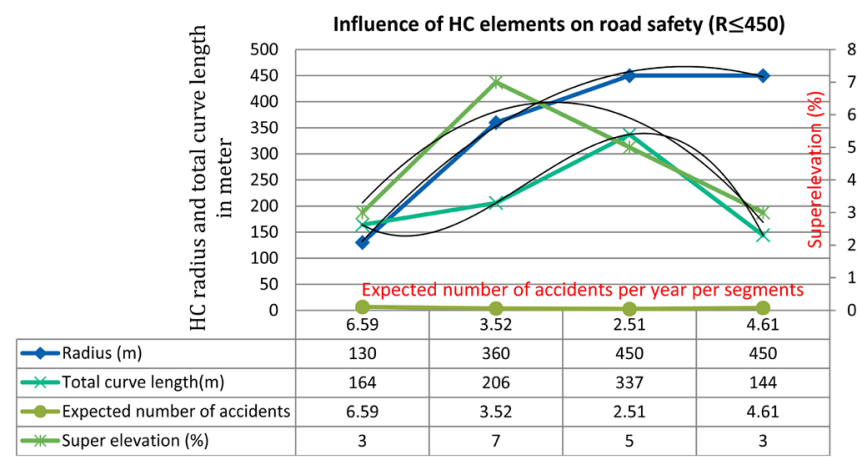

(a)

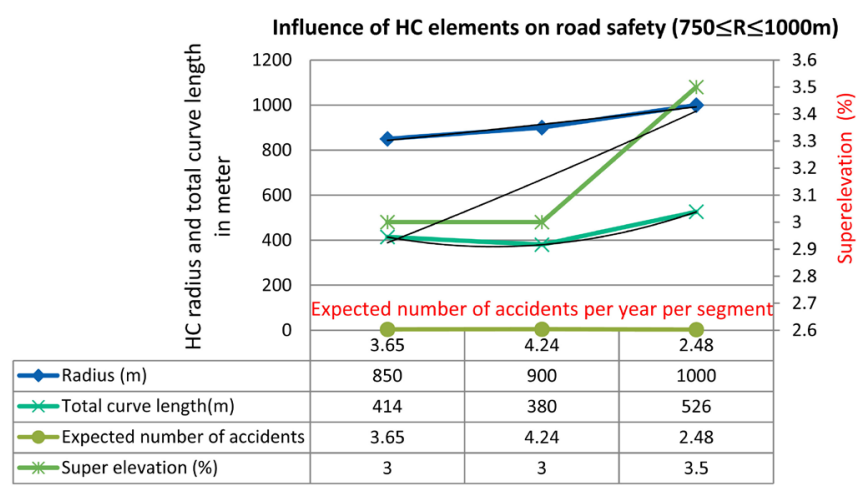

(c)

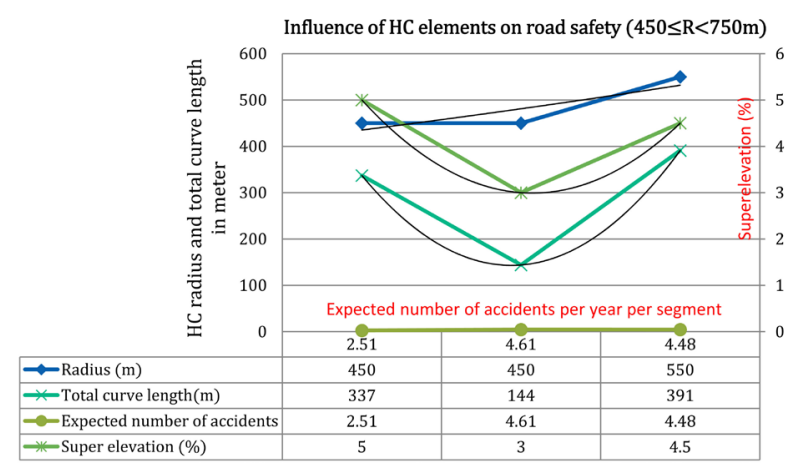

(b)

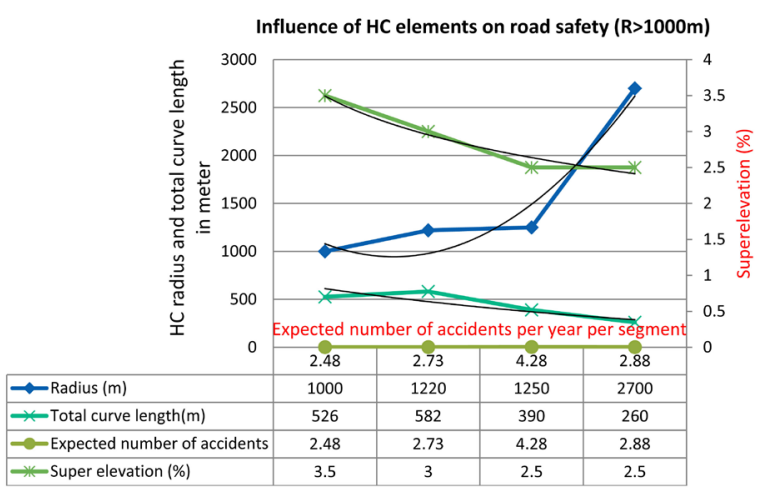

(d)

Figure 2. (a) Influence of HC radius, total curve length and super-elevation on road safety ( $\leq 450 \mathrm{~m}$ ); (b) Influence of $\mathrm{HC}$ radius, total curve length and super-elevation on road safety $(450 \leq \mathrm{R} \leq 750 \mathrm{~m})$; (c) Influence of HC radius, total curve length and super-elevation on road safety $(750 \leq \mathrm{R} \leq 1000 \mathrm{~m})$; (d) Influence of HC radius, total curve length and super-elevation on road safety $(\mathrm{R} \geq 1000 \mathrm{~m})$. Note: (a)-(d) were provided as left vertical axis represent curve radius and total curve length in meters, right vertical axis represents super-elevation in percent and each node along horizontal axis represents expected average frequency of accidents per $1.5 \mathrm{~km}$ road segment per year.

a) As shown in Figure 2(a), when all of $\mathrm{HC}$ elements such as the radius, total length and super-elevation were increased by $230 \mathrm{~m}$ (from 130 to 360), $42 \mathrm{~m}$ (from 164 to $206 \mathrm{~m}$ ) and 4 percentage points (from 3\% to 7\%) respectively, the frequencies of expected accidents significantly decreased by around $87 \%$. This is an indication of improving sharp horizontal curves improve road safety at a greater rate. As noted from an exhaustive literature review by Hauer [18] the number of road accidents increased when the radii of horizontal curves decreased. This finding is in conformity with findings of previous studies as indicated in the literature part.

b) Increasing radius of the curve by $90 \mathrm{~m}$ (from 360 to $450 \mathrm{~m}$ ), and length of curve by $131 \mathrm{~m}$ (from 206 to $337 \mathrm{~m}$ ), but decreasing super-elevation by 2 percentage points (from $7 \%$ to $5 \%$ ) also improves the safety of the road by $40 \%$ (Figure 2(a)). This step confirms that even though super-elevation of the curve decreased, due to a reasonable improvement of radius and total length of the curve the safety of the road improved at higher rate. This indicates that the safety of the road is too much sensitive to the radius of the curve for smaller radii (sharp curves). Furthermore, total curve length and road safety seem negatively 
correlated. This is probably due to the fact that when the length of transition curve increased the curve become flatter and flattening is expected to reduce the number of accidents.

c) In this step, Figure 2(a) shows that at constant radius $(\mathrm{R}=450 \mathrm{~m})$, reducing length of the curve by $193 \mathrm{~m}$ (from 337 to $144 \mathrm{~m}$ ) and super-elevation by 2 percentage points (from $5 \%$ to $3 \%$ ), increases substantial amount of accident frequencies and accounted for $83 \%$. This indicates that at aiven radius, super-elevation and length of horizontal curves were negatively associated with the number of expected accidents within the specified range of radius.

Accordingly, out of $144 \mathrm{~m}$ of total length of the shorter curve, circular curve length contributed only $48 \mathrm{~m}$ and the remaining $96 \mathrm{~m}$ were transition curves length, whereas the longer circular curve contributed $177 \mathrm{~m}$ from $377 \mathrm{~m}$ of total length (which was the sum of circular and transition curves) and the remaining $200 \mathrm{~m}$ was transition curve length. This can be explained by the fact that introducing very short circular curve length for sharper curve (i.e., $\mathrm{R} \leq 450 \mathrm{~m}$ ) HC along a high-speed rural road has a tendency to become a surprise to the drivers because such very short curve length makes the drivers to sense as if only small change in direction or the sharpness of the curve may not be imagined by drivers consequently they cannot reduce their speed accordingly.

Furthermore, increasing transition curve length has two main advantages. Firstly, it is forgiving because it gives more time to reduce the speed. Secondly, it is considered as flattening the curve because when transition curve increased central angle of the curve can also be increased. Therefore, the result indicated that increasing total length of the curve especially the transition part reduces substantial amount of accidents.

In addition to this, it is important to investigate the characteristics of those segments that the curves under investigation were located. The larger curve length HC located within segment 137, which was not included in the list of dangerous segment because it has experienced as much crash as expected from similar such types of roads (Table 1), whereas the shorter curve length HC found along segment 154 , which was ranked at $6^{\text {th }}$ places of dangerous segments. This is an indication of the availability of other risk contributing factors within segment 154 in addition to HC elements. Accordingly, in addition to HC elements, narrow culver, three horizontal curves within the segment, and sight distance problem due to inappropriate combination of horizontal and vertical curves were the identified risk contributing road factors along segment 154 .

Generally, the results found in this step indicated that short and sharp horizontal curves with small percentage of super-elevation were associated with higher number of expected accidents. These results supported the result of previous studies. Particularly, the results obtained by one study [9] by establishing the prediction model using NB distribution and a log link, which was in line with the result obtained here, concluded that the combination effect of sharp (small radius) and short curve length were associated with crash frequencies. One study [7] reviewed the result of other studies, which established the accident 
prediction model in curves located in two-lane suburban roads, indicated that road geometric design variables such as curve radius, curve length, super-elevation and others were identified as the contributing factor in the occurrence of traffic accidents [37]. This indicates that the finding of this paper discussed above is in conformity with findings of previous studies.

2) Radius of the curve in the range of $450 \leq R \leq 750 \mathrm{~m}$.

In this phase, as illustrated in Figure 2(b), the safety of the road has been estimated in two steps.

a) The first step has already discussed in part (1) step (c); therefore, the second step is discussed in the following section.

b) Accordingly, increasing all HC elements such as radius of the curve by 100 $\mathrm{m}$ (from 450 to $550 \mathrm{~m}$ ), length of curve by $247 \mathrm{~m}$ (from 144 to $394 \mathrm{~m}$ ) and super-elevation by 1.5 percentage points (from 3 to $4.5 \%$ ) improves the safety of a road only by $3.0 \%$. At this stage, even though all of the specified HC elements were increased reasonably at a higher rate, the safety of the road improved at a slower rate. This was unexpected result; therefore, further investigation of the characteristics of both segments are required. Accordingly, the smaller radius curve located along segment 154 (which was ranked in $6^{\text {th }}$ position), whereas the larger radius curve found on segment 165 (which was ranked in $1^{\text {st }}$ place).

Moreover, segment 165 has located near to mid-way between the road stretch that connects Hawassa city and Shashemene town with total length of $25 \mathrm{~km}$. This road stretch is characterized as very long tangent and only one sharp horizontal curve, which is part of segment 165 , is available within this road stretch resulting drivers experience high speed at the tangent section of the road. Furthermore, the place where segment 165 located was characterized as high number of non-motorized traffic due to village settlement around the road, sharp curve after long tangent, and inappropriate coordination of horizontal and vertical curves in both directions were noted as the most significant characteristics of this hazardous segment. As a result, drivers (especially unfamiliar one) may be surprised and may not be able to negotiate their speed in the tangent section and at the specified curved portion of the road segment. This is also an indication of the chain effect of several road section characteristics and traffic related factors make road safety analysis a complex matter.

3) Radius of the curve in the range of $750 \leq \mathrm{R} \leq 1000 \mathrm{~m}$.

In this phase, the influence of $\mathrm{HC}$ elements on road safety was considered in two steps as demonstrated in Figure 2(c).

a) At constant super-elevation (3\%), when the radius of the curve improved by $50 \mathrm{~m}$ (from 850 to $900 \mathrm{~m}$ ) and the length of the curve reduced by $34 \mathrm{~m}$ (from 414 to $380 \mathrm{~m}$ ) the frequencies of accident increased by $16 \%$. Even though the result supported previous results as indicated in the literature part, in the given radius increment only slight reductions of accidents were expected. For that reason, when we evaluated both of these segments, the smaller radius, $\mathrm{R}=850$ $\mathrm{m}$, curve located along segment 138 (which was ranked in $9^{\text {th }}$ position), whereas larger radius, $R=900 \mathrm{~m}$, curve located along segment 151 (which took the $3^{\text {rd }}$ 
places). As it has been investigated, in addition to HC elements the result obtained in this step was may be due to the effect of other road parameters like lane and shoulder width and number of curves per segment and others along segment 151.

b) Joint increase of radius of curve by $100 \mathrm{~m}$ (from 900 to $1000 \mathrm{~m}$ ), length of curve by $146 \mathrm{~m}$ (from 380 to $526 \mathrm{~m}$ ) and super-elevation by 0.5 percentage points (from $3 \%$ to $3.5 \%$ ) reduce the risk of the road by $71 \%$. Here is also only slight reduction of accidents can be expected as explained in the above paragraph. The result obtained in this step due to the increased values of each HC element was less than the corresponding values in phase-b; however, the percentage saved amounts of risk was not comparable and exaggerated when it was compared with the results of the previous studies.

Generally, this amount of accident reduction cannot be expected due to the improvement of only the specified HC elements. However, when we see their rank in Table 1 the smaller radius, $\mathrm{R}=900 \mathrm{~m}$, curve found along segment 151 (which took the $3^{\text {rd }}$ dangerous place), whereas larger radius, $\mathrm{R}=1000 \mathrm{~m}$, curve located within segment 131 (that was ranked in $21^{\text {st }}$ position). This can also be explained by the fact that the effect of the improvement of other road parameters contributed substantial amount of accident reduction when the road section transformed from segment 151 to segment 131. Accordingly, segment 151 was characterized as steep grade, passes through rolling terrain, high number of conflicts between through vehicles and local traffic because it passes through small town or village, narrow bridge and number of VC per segment.

4) Radius of the curve greater than or equals to $1000 \mathrm{~m}$.

In this phase the influence of HC element on road safety is described in the following three steps as shown in Figure 2(d).

a) Increasing both radius and length of the curve by $220 \mathrm{~m}$ (from 1000 to 1220 $\mathrm{m}$ ) and $56 \mathrm{~m}$ (from 526 to $582 \mathrm{~m}$ ) respectively, but reducing super-elevation by 0.5 percentage points (from 3.5 to $3 \%$ ) increase the number of accident by $10 \%$. As explained in the literature, due to a few increasing of radius of curve from $1000 \mathrm{~m}$ onward a slight increase of accident may be expected. Furthermore, the smaller radius, $\mathrm{R}=1000 \mathrm{~m}$, curve found along segment 131 which was ranked in $21^{\text {st }}$ position, whereas the larger radius, $\mathrm{R}=1220 \mathrm{~m}$, curve located within segment 133 which was ranked in $14^{\text {th }}$ place. This indicates that the effect of other road parameters like number of VC per segment and lane width were the expected parameters that may have an effect on increasing the number of accidents.

b) Increasing radius of the curve by $30 \mathrm{~m}$ (from 1220 to $1250 \mathrm{~m}$ ), but decreasing both the length of curve and super-elevation by $192 \mathrm{~m}$ (from 582 to $390 \mathrm{~m}$ ) and 0.5 percentage points (from 3 to $2.5 \%$ ) respectively mount the number of accidents by $57 \%$. Even though both circular and transition curves length and also super-elevation of the wider curve decreased the increased percentage of accidents were unexpected result. Therefore, further investigation of the characteristics of both segments is required. Accordingly, Table 1 shows that segment 
133 (which consist smaller radius, $\mathrm{R}=1220 \mathrm{~m}$, curve) was ranked in $14^{\text {th }}$ place, whereas segment 149 (consist larger radius, $\mathrm{R}=1250$, curve) was ranked in $4^{\text {th }}$ position. This assures that segment 149 most likely consist of other road parameters that may have higher risk factor than the characteristics of segment 133. To confirm this, from in-depth analysis of historical accident data and site investigation, it has been found that more risk indicating road factors such as narrow bridge and approach road, rolling terrain, and minor junction inside the horizontal curve were observed along segment 149, however, one minor junction outside the curve and mild grade were the observed characteristics of segment 133. Furthermore, traffic police report emphasized that narrow bridge and both approach roads were the most accident-prone location due to sight distance problem and substantial pedestrian movement along segment 149.

c) At constant super-elevation (2.5\%), increasing radius of the curve by 1450 $\mathrm{m}$ (from 1250 to $2700 \mathrm{~m}$ ), but reducing curve length by130 m (from 390 to 260 $\mathrm{m}$ ) improve the safety of the road by $48.0 \%$. The result obtained in this step was also more than the expected value. Despite the fact that increasing the radius of the curve up to $2700 \mathrm{~m}$ can be considered as straightening of the curve, this much reduction of accident probably due to the effect of other road parameters. This can be proved that the smaller and the larger radius curves located within segment 149 (ranked at $4^{\text {th }}$ place) and 135 (which was not dangerous segment) respectively. This may be associated with less risk indicating road parameters along segment 135 .

\subsubsection{Influence of Number of HC Per $1.5 \mathrm{Km}$ Segment Length}

In this paper, it has been tried to estimate the joint effect of more than one road parameter on road safety at a time; however, most of the time it is difficult to differentiate the effect of one road parameter over the other on road safety. For instance, Figure 3(a) and Figure 3(b) are typical example of this problem as the plots have been prepared to estimate the safety of a road due to the joint effect of number of $\mathrm{HC}$ and VC per segment and grade of the road (for a grade range of less or equals to $3 \%$ and greater than $3 \%$ respectively). Even though the Figures, generally, indicate that the expected number of accidents increased with the improvement of grade, number of $\mathrm{HC}$ and VC, it is better to analyze the effect on road safety of each road parameter separately. So that, the effect of the number of HCs per segment on the corresponding average expected frequencies of accidents are given in Table 2.

The influence of frequencies of HC per segment on road safety were estimated and given in Table 2. The result showed that the highest frequencies of accident exhibited on road segment, which have the highest number of $\mathrm{HC}$ (i.e. four

Table 2. Effect of number of HC on road safety.

\begin{tabular}{cccccc}
\hline Number of HC per Segment & 0 & 1 & 2 & 3 & 4 \\
\hline Average EB Safety Estimate per Year & 2.16 & 3.20 & 3.49 & 4.41 & 6.33 \\
Percentage change of EB Safety Estimate & & 47.94 & 8.95 & 26.52 & 43.48 \\
\hline
\end{tabular}




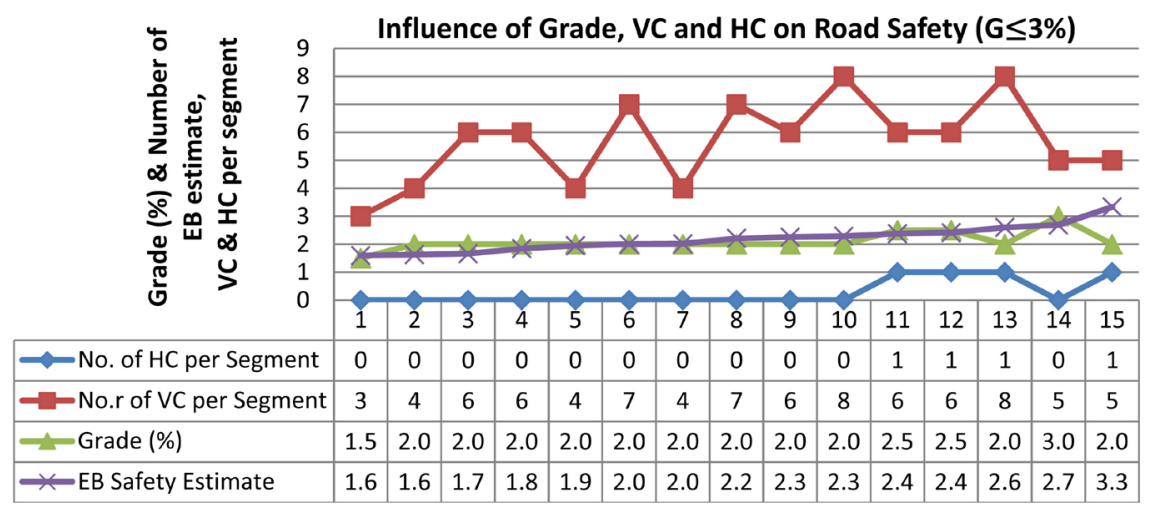

(a)

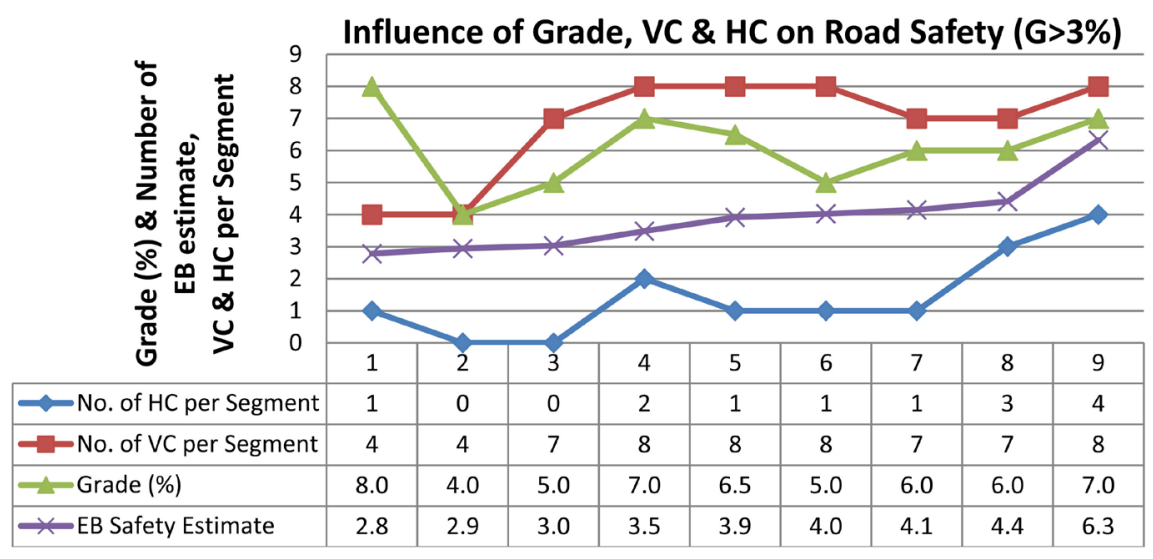

(b)

Figure 3. (a) Influence of grade and number of VC and HC per segment on road safety; (b) Influence of grade and number of VC and HC per segment on road safety.

curves per $1.5 \mathrm{~km}$ road segment) and the lowest average frequencies of accidents encountered on no curve segment.

As expected, the result indicated that the number of HC per each segment directly associated with the average frequencies of expected accidents per year as shown in Table 2. The possible explanation of increasing the number of expected accidents while increasing the number of HC per segment was due to the reason that the additional efforts required by the driver (i.e. workload imposed on driver) to control the stability of the vehicle. Furthermore, while driving along a road, if segments of the road were arranged from no curve (tangent) segment up to four numbers of curves per segment in a consecutive increasing order, the highest increment(around 48\%) of involving in accident risk was observed when the road section changed from tangent to one curve per segment as indicated in Table 2. This result indicated that the first horizontal curve after a long tangent experienced as much as 1.5 times the number of accidents that can be occurred along tangent section. This result is within the range of findings of previous studies because some few studies stated that horizontal curves experienced crash rate of up to four times the rates on tangent sections [5] [6]. And followed by from three curves to four curves per segment section of the road and 
accounted around $43 \%$. The least risk exhibited from one curve to two curves per segment road section and accounted for around $9 \%$.

The following discussion presents the possible reason for each scenario. Accordingly, when the road is straight the driver does not expect sudden sharp curve ahead; therefore, a sharp (i.e. lower radius) curve after a long tangent may increase accident risk due to the fact that significant operating speed variations between tangent and curved section of the road. This is the possible reason why highest percentage increment of accident risk exhibited when a road section changed from no curve to one curve per segment road section. The possible explanation for the second highest percentage increment of accident risk was due to the reason that driving task became difficult or driver workload increased when the road section changed from three to four numbers of curves per $1.5 \mathrm{~km}$ road segment. When the road section changed from one curve to two curves per segment, on the other hand, the driver experiences or expects there to be additional curves on the road ahead, therefore, they tend to decrease their speed. Consequently, the involvement in accidents increased only by a few percentage. Furthermore, Figure 4 shows that a plot of expected average yearly frequencies of accident (as a dependent y-variable,) verses number of HCs per segment (as an independent $\mathrm{x}$-variable). The plot as indicated by the best-fit regression line shows that exponential function $\left(\mathrm{y}=2.2448^{\star} \exp (0.2468 \mathrm{x})\right.$, with $\left.\mathrm{R}^{2}=0.96\right)$ was established between the dependent and independent variables under this study area.

\subsubsection{Influence of Number of VC per Segment}

Table 3 and Figure 5 reveal that when the number of vertical curves (VC) per segment increased the frequencies of accidents also increased except from 5 to 6 numbers of VCs per segment. Furthermore, the rate of increment of frequencies of expected accidents due to consecutive increasing of number of VCs from 3 up to 8 per segment are also shown in Table 3 in similar fashion as that of number of HC per segment. Accordingly, the highest increment of involving in accident risk were observed when the road section transformed from 6 to 7 and 3 to 4 number of VCs per segment and they accounted for around 50 and $42 \%$ respectively. The probable reasons for these are similar with explanation given in the previous section (i.e., from 3 to $4 \mathrm{VC}$ per segment associated with high speed variation and from 6 to 7 associated with driver workload).

Generally, increasing number of VCs per $1.5 \mathrm{~km}$ road segment usually associated with restricted sight distance at the crest of VC, breaking distance on downhill, insufficient combination with $\mathrm{HC}$, and other related problems increases driver workload. On the other hand, when the road section transformed from 5 to 6 numbers of VCs per segment the frequency of accident unexpectedly decreased by around $30 \%$. This is may be due to the effect of other road parameters. In addition, Figure 5 shows that when the number of VC (as independent variable) and average frequencies of accidents (as response variable) were correlated, the best-fit polynomial relationship was observed between the dependent and independent variables in this study area (with $\mathrm{R}^{2}=0.84$ ). 
Influence of number of HC per $1.5 \mathrm{~km}$ road segment on road safety

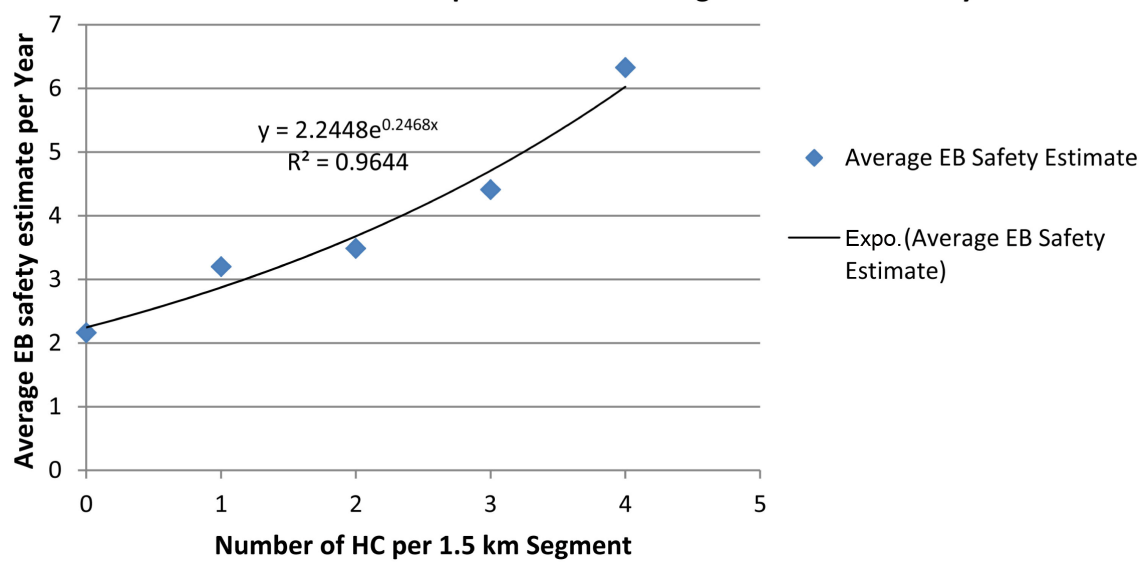

Figure 4. Number of HC against EB safety estimate per year.

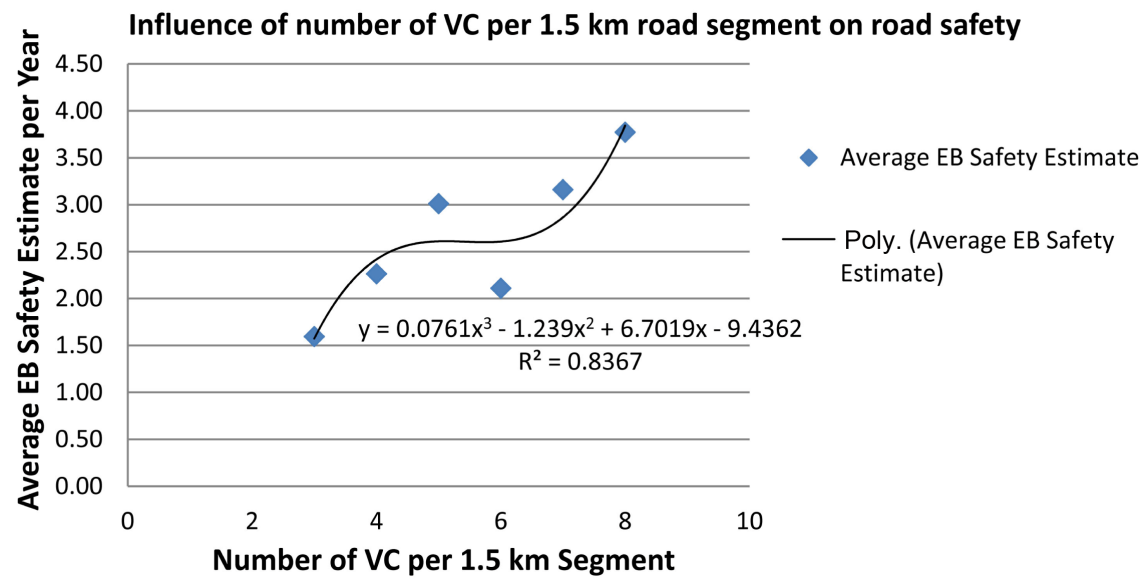

Figure 5. Number of VC verses EB safety estimate.

Table 3. Effect of number of VC on road safety.

\begin{tabular}{ccccccc}
\hline Number of VC per Segment & 3 & 4 & 5 & 6 & 7 & 8 \\
\hline Average BE Safety Estimate per Year & 1.59 & 2.26 & 3.01 & 2.11 & 3.16 & 3.77 \\
Percentage change of EB Safety Estimate & & 41.98 & 33.05 & -29.92 & 49.75 & 19.38 \\
\hline
\end{tabular}

\subsubsection{Influence of Grade}

The effect of grade on road safety was considered, as Table 4 illustrates, in three categories of grades. Result from the Table shows that grade of a road was positively correlated with average number of accidents per segments per year. Accordingly, flat road section (i.e. $\mathrm{G} \leq 3 \%$ ) record less frequencies of crashes than mild $(3 \%<\mathrm{G} \leq 6 \%)$ and mild gradient record less number of crash when compared with steep $(\mathrm{G}>6 \%)$ gradients. On sections with high gradient, safety problems may occur from speed differences between passenger cars and heavy vehicles (e.g. heavy vehicles idling on upgrade sections), as well as vehicles braking on downhill sections (e.g. increases in braking distances).

On the other hand, an increase of $69.35 \%$ and $11.22 \%$ in number of accidents occurred at links with flat grade compared with links with mild grade and at 
Table 4. Effect of grade on road safety.

\begin{tabular}{cccc}
\hline Grade, G (\%) & $\mathrm{G} \leq 3 \%$ & $3 \%<\mathrm{G} \leq 6 \%$ & $\mathrm{G} \geq 6 \%$ \\
\hline Average EB Safety Estimate per Year & 2.19 & 3.71 & 4.13 \\
Percentage change of EB Safety Estimate & & 69.35 & 11.22 \\
\hline
\end{tabular}

links with mild grade compared with links with steep grade respectively. The probable reason for this result is with the fact that drivers tend to travel at higher speeds on flat grades than on mild and steep grades.

\subsubsection{Combination Effect of Horizontal and Vertical Alignments on Road Safety}

An inefficient combination of horizontal and vertical alignment may lead to road safety problems, even when the horizontal and the vertical alignment are separately correct and according to the standards. Poor coordination of horizontal and vertical alignments can create locations where the available sight distance drops below the required sight distance [21].

As indicated in the review part, the coincidence of a right horizontal curve and a crest vertical curve may, under certain conditions, lead to significant limitation of the available sight distance and prevent the prompt perception of the curve. For instance, segments 165, 152, 154 and 148, were good examples as shown in Table 1 , which were ranked in $1^{\text {st }}, 2^{\text {nd }}, 6^{\text {th }}$ and $7^{\text {th }}$ position respectively consist the specified combination of horizontal and vertical curves.

Similarly, the coincidence of a left horizontal curve and a sag vertical curve may create a false impression of the degree of curvature (i.e. the horizontal curve may seem to have a higher radius than the actual), and may contribute to increased accident risk. For instance, segments 165, 152 and 154, were good examples that consists the specified combination of horizontal and vertical curves, were ranked in $1^{\text {st }}, 2^{\text {nd }}$ and $6^{\text {th }}$ position respectively as indicated in Table 1.

\subsubsection{Influence of Lane and Shoulder Width}

Both lane and shoulder width were taken from site measurement at the probable accident-prone location of each segment. Accordingly, Table 5 and Table 6 present at $0.15 \mathrm{~m}$ and $0.2 \mathrm{~m}$ increment of lane and shoulder widths respectively. Therefore, the width of lane and shoulder used for analysis purpose for each segment was the average width of representative accident-prone location. These accidents prone locations were identified based on in-depth analysis of accident record and some evidence from an interview with the traffic police officers supported such allegation.

According to field measurement, average width of lane ranges from 3.2 to 3.5 $\mathrm{m}$. These widths were less than the base width. According to HSM [2], base widths are equals to $3.66 \mathrm{~m}$ for lane and $1.83 \mathrm{~m}$ for shoulder. As shown in Table 5 , widening average lane width by $0.15 \mathrm{~m}$, from 3.20 to $3.35 \mathrm{~m}$ and from 3.35 to $3.50 \mathrm{~m}$, around 22.90 and $21.52 \%$ reduction in accidents were observed respectively. The result obtained here is in conformity with the result of Berhanu's 
Table 5. Influence of lane width on road safety.

\begin{tabular}{cccc}
\hline Lane width in meter $(\mathrm{m})$ & 3.20 & 3.35 & 3.50 \\
\hline Average BE Safety Estimate per Year & 3.97 & 3.06 & 2.40 \\
Percentage change of EB Safety Estimate & & -22.90 & -21.52 \\
\hline
\end{tabular}

The negative sign indicates reduction of expected accidents.

Table 6. Influence of shoulder width on road safety.

\begin{tabular}{cccc}
\hline Shoulder in width $(\mathrm{m})$ & 0.80 & 1.00 & 1.20 \\
\hline Average EB Safety Estimate per Year & 3.59 & 2.37 & 1.79 \\
Percentage change of EB Safety Estimate & & -33.95 & -24.61
\end{tabular}

The negative sign indicates reduction of expected accidents.

study [3] that the reduction of accident on rural two-lane road as a result of widening lane from $3.00 \mathrm{~m}$ up to base width.

The widths of shoulder that have been considered in this study were only the actual existing paved portion because most of the deteriorated and unpaved parts were not properly functioning. Table 6 provides the influence of shoulder width on road safety. Accordingly, widening average shoulder width by $0.2 \mathrm{~m}$, from 0.8 to $1.0 \mathrm{~m}$ and from 1.0 to $1.2 \mathrm{~m}$, around $33.95 \%$ and $24.61 \%$ reduction in accidents were observed respectively. This is an indication that safety of rural two-lane road is too much sensitive to lane and shoulder widths. Since this finding is in conformity with the result of several previous studies, adequate shoulder width has to be provided in order to make safe recovery of vehicles when it veer off the road. In general, this study concludes that wider lane and/or shoulder widths produces fewer accidents. In addition, only a few widening of lane and/or shoulder width would result huge reduction of accidents.

In general, in average $22 \%$ and $29 \%$ of accident frequency were reduced due to $0.15 \mathrm{~m}$ and 0.2 land and shoulder width improvement respectively.

\section{Conclusions}

The analysis showed that short and sharp (i.e., $\mathrm{R} \leq 450 \mathrm{~m}$ ) horizontal curves were associated with higher crash frequencies. For wider curves (i.e., $\mathrm{R}>750 \mathrm{~m}$ ), the effect of horizontal curve elements on road safety is found to be not consistent and hence it may be highly affected by the availability of other risk indicating road parameters rather than horizontal curves elements. Generally, this study found that the frequencies of average accidents decreased as the radius of the curve, transition curve length and super-elevation of horizontal curves jointly and/or alone increased.

The numbers of horizontal and vertical curves per $1.5 \mathrm{~km}$ road segments were positively correlated with the average accident frequencies. Furthermore, it was also found that the first horizontal curve after a long tangent was the most critical curve and the risk was 1.5 times greater than that of the tangent section.

Grade of the road was positively correlated with average number of accidents 
per segments. Furthermore, an increase of around $69 \%$ and $11 \%$ in number of accidents identified in this study when the road section transformed from flat to mild grade and from mild to steep grades respectively.

Wider lane and/or shoulder width produces fewer numbers of average accident. In average, $22 \%$ and $29 \%$ of accident frequencies have been reduced due to 0.15 and $0.2 \mathrm{~m}$ land and shoulder width improvement respectively.

Finally, the study concluded that even though traffic police report underestimated the influence of road geometry on road safety in Ethiopia, substantial improvements of expected number of accidents have been quantified when the road section parameters improved (or transformed from less to high risk indicating road factors) as indicated in the above sections.

\section{Limitation}

There exists a limitation in this study because the vehicle factors and human factors were not correlated with expected number of expected accidents. Accordingly, the effect of vehicles defect and human errors were considered to be constant for this study. Therefore, it is recommended that further research should be conducted to address the issue.

\section{Acknowledgements}

The author would like to acknowledge Department of Civil Engineering, Institute of Technology, Hawassa University for their help and encouragement to conduct this research. The author is particularly grateful to Mr. Edilu Shona (Asst. Professor) for his cross assistance and valuable comments through reading the draft manuscript of this paper.

\section{Conflicts of Interest}

The author declares no conflicts of interest regarding the publication of this paper.

\section{References}

[1] Haddon, W. (1972) A Logistic Framework for Categorizing Highway Safety Phenomena and Activity. The Journal of Trauma, 12, 193-207. https://doi.org/10.1097/00005373-197203000-00002

[2] American Association of State Highway and Transportation Officials (AASSHTO) (2009) Highway Safety Manual. AASSHTO, Washington DC.

[3] Berhanu, G. (2000) Effects of Road and Traffic Factors on Road Safety in Ethiopia. Ph.D. Thesis, NorwegianUniversity of Science and Technology, Trodhium, Norway.

[4] Abebe, M.T. and Belayneh, M.Z. (2018) Identifying and Ranking Dangerous Road Segments A Case of Hawassa-Shashemene-Bulbula Two-Lane Two-Way Rural Highway, Ethiopia. Journal of Transportation Technologies, 8, 151-174. https://doi.org/10.4236/jtts.2018.83009

[5] Elvik, R. and Vaa, T. (2004) The Handbook of Road Safety Measures. Elsevier Science, Amsterdam. 
[6] Aram, A. (2010) Effective Safety Factors on Horizontal Curves of Two-Lane Highways. Journal of Applied Sciences, 10, 2814-2822. https://doi.org/10.3923/jas.2010.2814.2822

[7] Karimi, A. and Kashi, E. (2018) Investigating the Effect of Geometric Parameters Influencing Safety Promotion and Accident Reduction (Case Study: Bojnurd-Golestan National Park Road). Cogent Engineering, 5, Article ID: 1525812.

[8] Hameed, M. (2013) The Influence of Road Geometric Design Elements on Highway Safety. International Journal of Civil Engineering and Technology, 4, 146-162.

[9] Bauer, K.M. and Harwood, D.W. (2013) Safety Effects of Horizontal Curve and Grade Combinations on Rural Two-Lane Highways. Transportation Research Record, 2398, 37-49. https://doi.org/10.3141/2398-05

[10] European Road Safety Observatory (2006) Road Safety Management. http://www.erso.eu/

[11] Hauer, E. (1999) Safety and the Choice of Degree of Curve. Transportation Research Record, 1665, 22-27. https://doi.org/10.3141/1665-04

[12] Department of Transportation (2007) Safety Handbook for Secondary Roads, USA.

[13] Ethiopian Roads Authority (2013) Geometric Design Manual. Addis Ababa, Ethiopia.

[14] Stewart, D. and Chudworty, C.J. (1990) A Remedy for Accidents at Bends. Traffic Engineering and Control, 31, 88-93.

[15] Brenac, T. and Annex, I. (1994) Curves on Two-Lane Roads, Safety Effects of Road Design Standards. SWOV, Leidschendam, the Netherlands.

[16] Kanellaidis, G. (1991) Aspects of Highway Super-Elevation Design. ASCE Journal of Transportation Engineering, 117, No 2. https://doi.org/10.1061/(ASCE)0733-947X(1991)117:6(624)

[17] Harwood, D.W., Council, F.M., Hauer, E., Hughes, W.E. and Vogt, A. (2000) Prediction of the Expected Safety Performance of Rural Two-Lane Highways. Paper No. FHWA-Rd-99-207, Federal Highway Administration, Washington DC.

[18] Hauer, E. (2000) Safety of Horizontal Curves, Review of Literature forthe Interactive Highway Safety Design Model. http://www.roadsafetyresearch.com/

[19] Matthews, L.R.and Barnes, J.W. (1988) Relation between Road Environment and Curve Accidents. Proceedings of 14th ARRB Conference, Canberra, 28 August-2 September 1988, 105-120.

[20] Obaidat, M.T. and Ramadan, T.M. (2012) Traffic Accidents at Hazardous Locations of Urban Roads. Jordan Journal of Civil Engineering, 6, 436-447.

[21] Hassan, Y., Sayed, T. and Bidulka, S. (2002) Influence of Vertical Alignment on Horizontal Curve Perception: Phase II, Modelling Perceived Radius. Transportation Research Record, 1796, 24-34. https://doi.org/10.3141/1796-03

[22] Institution of Highways and Transportation (IHT) (1990) Guidelines for Accident Reduction and Prevention. International Edition, London.

[23] Smith, B. and Lamm, R. (1993) Coordination of Horizontal and Vertical Alignment with Regard to Highway Aesthetics. Transportation Research Record Journal of the Transportation Research Board, 1445, 73-85.

[24] Kiran, B.N., Kumaraswamy, N. and Sashidhar, C. (2017) A Review of Road Crash Prediction Models for Developed Countries. American Journal of Traffic and Transportation Engineering, 2, 10-25.

[25] Jerry, P., John, S., Wendel, R. and Dominique, L. (2009) Impact of Shoulder Width 
and Median Width on Safety. NCHRP Report 633. Transportation Research Board of the National Academies, Washington DC.

[26] Transportation Research Board (1987) Designing Safer Roads, Special Report 214. Transportation Research Board, Washington DC, 319.

[27] Landge, V.S., Jain, S.S. and Parida, M. (2006) Modeling Traffic Accidents on Two Lane Rural Highways under Mixed Traffic Conditions. 87 th Annual Meeting of Transportation Research Board.

[28] Hauer, E. (1997) Observational before-after Studies in Road Safety: Estimating the Effect of Highway and Traffic Engineering Measures on Road Safety. Pergamon, Oxford, $289 \mathrm{p}$.

[29] Shen, J. and Gan, A. (2003) Development of Crash Reduction Factors: Methods, Problems, and Research Needs. Transportation Research Record: Journal of the Transportation Research Board, 1840, 50-56. https://doi.org/10.3141/1840-06

[30] Huang, H., Chin, H. and Haque, M. (2009) Empirical Evaluation of Alternative Approaches in Identifying Crash Hot Spots Naive Ranking, Empirical Bayes, and Full Bayes Methods. Transportation Research Record, 2103, 32-41. https://doi.org/10.3141/2103-05

[31] Xie, K., Ozbay, K., Yang, H. and Yang, D. (2018) A New Methodology for Before-After Safety Assessment Using Survival Analysis and Longitudinal Data. Risk Analysis, 39, 1342-1357. https://doi.org/10.1111/risa.13251

[32] Hauer, E., Harwood, D.W., Council, F.M. and Griffith, M.S. (2002) Estimating Safety by the Empirical Bayes Method: A Tutorial. Transportation Research Record: Journal of the Research Board, 1784, 126-131. https://doi.org/10.3141/1784-16

[33] Brimley, B.K. (2011) Calibration of the Highway Safety Manual Safety Performance Function and Development of Jurisdiction Specific Models for Rural Two-Lane Two-Way Roads in Utah. All Theses and Dissertations, 2611. https://scholarsarchive.byu.edu/etd/2611

[34] Persaud, B., Lyon, C. and Nguyen, T. (1999) Empirical Bayes Procedure for Ranking Sites for Safety Investigation by Potential for Safety Improvement. Transportation Research Record: Journal of the Research Board, 1665, 7-12. https://doi.org/10.3141/1665-02

[35] United Nations (2017) World Population Prospects: The 2017 Revision. United Nations Department of Economic and Social Affairs, Population Division. https://Esa.Un.Org

[36] Africa::Ethiopia-The World Factbook-Central Intelligence ...-Cia. https://www.cia.gov/library/publications/the-world-factbook/geos/print et.html

[37] Saffarzadeh, M. and Shabani, S. (2007) An Accident Forecasting Model for Horizontal Curves in Intercity Roads. Journal of Transportation Research, 4, 9-a-50. 